\title{
Control of Citrus Green Mold by Carbonate and Bicarbonate Salts and the Influence of Commercial Postharvest Practices on Their Efficacy
}

\author{
Joseph L. Smilanick and Dennis A. Margosan, USDA-ARS, Fresno, CA 93727; Franka Mlikota, Institute for \\ Adriatic Crops, 21000 Split, Croatia; Josep Usall, Centre UdL-IRTA, 25198 Lleida, Catalonia, Spain; and Ibrahim \\ F. Michael, Advanced Packinghouse Systems, LLC, Fresno, CA 93721
}

\begin{abstract}
Smilanick, J. L., Margosan, D. A., Mlikota, F., Usall, J., and Michael, I. F. 1999. Control of citrus green mold by carbonate and bicarbonate salts and the influence of commercial postharvest practices on their efficacy. Plant Dis. 83:139-145.

The toxicity to Penicillium digitatum and practical use of carbonate and bicarbonate salts to control green mold were determined. The effective dose $\left(\mathrm{ED}_{50}\right)$ concentrations to inhibit the germination of $P$. digitatum spores of sodium carbonate (SC), potassium carbonate, sodium bicarbonate (SBC), ammonium bicarbonate, and potassium bicarbonate were 5.0, 6.2, 14.1, 16.4 , and $33.4 \mathrm{mM}$, respectively. All were fungistatic because spores removed from the solutions germinated in potato dextrose broth. SC and SBC were equal and superior to the other salts for control of green mold on lemons and oranges inoculated $24 \mathrm{~h}$ before treatment. When sodium content and high pH must be minimized, SBC could replace SC. Furthermore, because a higher proportion of $\mathrm{NaOCl}$ would be present in the active hypochlorous acid at the lower $\mathrm{pH}$ of SBC compared to SC, sanitation of the SBC solution should be easier to maintain. $\mathrm{NaOCl}$ (200 $\mu \mathrm{g} / \mathrm{ml}$ ) added to SBC at $\mathrm{pH} 7.5$ improved green mold control. Rinse water as high as $50 \mathrm{ml}$ per fruit applied after SC did not reduce its effectiveness; however, high-pressure water cleaning after SC did. Conversely, high-pressure water cleaning of fruit before SC improved control of green mold. The risk of injury to fruit posed by SC treatment was determined by immersing oranges for $1 \mathrm{~min}$ in $3 \%$ (wt/vol) SC at $28,33,44,50,56$, or $61^{\circ} \mathrm{C}\left( \pm 1^{\circ} \mathrm{C}\right)$ and followed by storage for 3 weeks at $10^{\circ} \mathrm{C}$. Rind injuries occurred only after treatment at 56 and $61^{\circ} \mathrm{C}$. The risk of injury is low because these temperatures exceed that needed for control of green mold. SC was compatible with subsequent imazalil and biological control treatments.
\end{abstract}

Bicarbonates and carbonates are common food additives for leavening, $\mathrm{pH}$-control, taste, texture modification, and spoilage control (8). They also control many plant pathogens $(12,19,29,33,41)$. Regulatory barriers to their use are few; most are classified as generally recognized as safe by the US Food and Drug Administration for many applications. In 1997, the US Environmental Protection Agency declared that bicarbonates were exempt from residue tolerances on all agricultural commodities, and the United States Department of Agriculture classified many carbonates and bicarbonates as approved ingredients on products labeled "organic" in proposed regulations to standardize organic practices. Brief immersion of citrus fruit in solutions of sodium bicarbonate $\left(\mathrm{NaHCO}_{3}\right)$ or sodium carbonate $\left(\mathrm{Na}_{2} \mathrm{CO}_{3}\right.$, soda ash) reduces the subsequent incidence of postharvest green mold, caused by Peni-

Corresponding author: Joseph L. Smilanick

E-mail: Jsmilanick@aol.com

Accepted for publication 15 October 1998.

Publication no. D-1998-1123-01R

This article is in the public domain and not copyrightable. It may be freely reprinted with customary crediting of the source. The American Phytopathological Society, 1999. cillium digitatum $(2,13,20,23,26,31,35)$. This practice is inexpensive, poses a minimal risk of injury to the fruit, and can be a useful tool in the management of fungicide resistant isolates, which have become particularly problematic $(6,11)$. Its effectiveness can approach that of the fungicides employed for this purpose (36), and in general is superior to other treatments that are alternatives to fungicides, such as heat $(5,7,21,36,37)$ or biological control $(4,34)$. Sodium carbonate (SC) controls green mold even when applied long after inoculation; the incidence of infections from wounds on lemons inoculated $48 \mathrm{~h}$ before treatment was reduced more than $90 \%$ (36). Control of green mold after inoculation is important because most infections occur through wounds inflicted during or just after harvest $(13,16,32)$, and often a day or more can elapse before treatments are applied. Previously, we developed a model describing the influence of SC concentration, temperature, and duration of contact on the control of green mold on oranges, where SC had been seldom used (35). Like heat and biological treatments applied to citrus, SC only reduces the incidence of green mold but, unlike fungicides, does not suppress the subsequent production of spores on those fruit that do decay. The deposition of spores on adjacent healthy fruit, termed "soilage," makes cleaning of the remaining fruit necessary (10). SC use has become increasingly popular in California; however, certain aspects of the practical use of SC are incompletely known. Although both SC and sodium bicarbonate (SBC) have been recommended for this purpose, they have not been compared to each other or with ammonium or potassium carbonate salts. This information is of particular interest because the quality of water discharged from SC tanks can exceed $\mathrm{pH}$ and sodium content tolerances in some areas; the use of other solutions of lower $\mathrm{pH}$, lower sodium content, or containing salts of less regulatory concern could alleviate this problem.

The inhibitory activity of carbonate or bicarbonate solutions against many microorganisms (28), including $P$. digitatum $(22,26)$, is low and generally fungistatic. Therefore, it is probable that a residue of carbonate or bicarbonate must remain on the fruit, or at least within the wound infection courts occupied by this pathogen, for the treatment to control green mold. Winston (40) showed that the efficacy of the immersion of citrus fruit in heated solutions of borax-boric acid to control postharvest decay, in regimes very similar to those of SC, was greatly reduced by subsequent rinsing of the fruit with large volumes of water, and he stated some optimal level of post-treatment rinsing should be determined empirically where this treatment is used. It is likely that post-treatment rinsing also will influence the effectiveness of carbonate or bicarbonate solutions, because borax-boric acid and carbonate-bicarbonate solutions are both fungistats and of similar effectiveness (22). Rinsing is an important issue because the solutions must be rinsed off the fruit surface after treatment to prevent the deposition of the salts on brushes and belts of packing and sorting equipment, and to prevent phytotoxicity, seen as staining and desiccation of the fruit rind. Another process required after harvest is cleaning of the fruit. Introduced recently for this purpose are high-pressure water washers that blast scale insects, sooty mold, and soil from fruit with water applied at high pressure (150 to 500 psi or 1,000 to $3,500 \mathrm{kPa}$ ) in very high volumes. High pressure washing can be applied at any step after harvest before the application of waxes.

Other issues of concern for packinghouse managers contemplating the adop- 
tion of a carbonate treatment include the risk of injury to fruit the treatment could pose, particularly for navel orange cultivars. Most of these cultivars were introduced since the original carbonate research was published $(2,17,21,23)$, and managers state these are very susceptible to cosmetic defects of the rind that develop after harvest, such as pitting. Another concern is the influence of carbonate treatment on the effectiveness of subsequent fungicide or biological control treatments.

Objectives in the present work were to (i) compare the fungitoxicity and disease control effectiveness of SC, potassium carbonate, SBC, potassium bicarbonate, and ammonium bicarbonate; (ii) determine the influence of water rinse volume applied after SC treatment on the effectiveness of the treatment to control green mold; (iii) investigate the influence of high-pressure water washing on SC effectiveness; (iv) determine if fruit are susceptible to injury by SC treatment, particularly early season oranges; and (v) determine the influence of prior SC treatment on the effectiveness of subsequent imazalil or biological control treatments.

\section{MATERIALS AND METHODS}

Inoculum preparation. $P$. digitatum (Pers.:Fr.) Sacc. isolate M6R (obtained from J. W. Eckert, University of California, Riverside) was cultured for 1 to 2 weeks on potato dextrose agar. Spores were harvested by adding $5 \mathrm{ml}$ of water containing $0.05 \%$ Triton X-100 to the Petri dish, rubbing the surface with a sterile glass rod, and passing the suspension through two layers of cheese cloth. The suspension was diluted with water to an absorbance of 0.1 at $425 \mathrm{~nm}$ determined with a spectrophotometer; this density contains approximately $10^{6}$ spores $/ \mathrm{ml}$ (9).

In vitro inhibition of spores of $P$. digitatum by bicarbonate and carbonate solutions. Potato dextrose broth containing $0,2.5,5.0,10.0,25.0$, and $50.0 \mathrm{mM}$ of SC $\left(\mathrm{Na}_{2} \mathrm{CO}_{3}\right)$, potassium carbonate $\left(\mathrm{K}_{2} \mathrm{CO}_{3}\right)$, SBC $\left(\mathrm{NaHCO}_{3}\right)$, ammonium bicarbonate $\left(\mathrm{NH}_{4} \mathrm{HCO}_{3}\right)$, or potassium bicarbonate $\left(\mathrm{KHCO}_{3}\right)$ was prepared in 4-ml volumes from anhydrous salts (Sigma Chemical Co., St. Louis). Three replicates of each were prepared, and 10,000 spores of $P$. digitatum were added to each replicate. In the first test, the $\mathrm{pH}$ of each solution was not controlled and increased with increase in salt concentration. After $18 \mathrm{~h}$ at $22^{\circ} \mathrm{C}$ $\left( \pm 1^{\circ} \mathrm{C}\right), 100 \mu \mathrm{l}$ of acid fuchsin solution $(0.2 \% \mathrm{wt} / \mathrm{vol}$ acid fuchsin in a solution containing one part acetic acid and one part $95 \%$ ethanol) was added to each well to stop further germination and the percentage of germinated spores determined by observation of 100 to 150 spores within each replicate with an inverted compound microscope $(200 \times)$. No acid fuchsin was added to a fourth replicate well of each solution; the spores were withdrawn from this well with a Pasteur pipette, suspended in sterile distilled water followed by lowspeed centrifugation, and re-suspended in potato dextrose broth for an additional 18 h. In a second test, the bicarbonate salts alone were tested at similar $\mathrm{pH} ; 50 \mathrm{mM}$ phosphate buffer was included and the final $\mathrm{pH}$ of the solutions was $7.3( \pm 2)$. After $18 \mathrm{~h}$ at $22^{\circ} \mathrm{C}\left( \pm 1^{\circ} \mathrm{C}\right)$, acid fuchsin was added to each well to stop further germination and the percentage of germinated spores determined as previously described. The experiments were conducted twice.

Fruit inoculation. Lemons (Citrus limon (L.) Burm.) or oranges (C. sinensis (L.) Osbeck) that had been commercially harvested no more than 2 days prior to use were randomized and inoculated with $P$. digitatum $24( \pm 2) \mathrm{h}$ before treatments were applied. This inoculation method simulates infections that occur under commercial conditions and has been recommended for determining the effectiveness of fungicides (9). Fruit were inoculated by immersing a stainless steel rod with a probe tip $1 \mathrm{~mm}$ wide and $2 \mathrm{~mm}$ in length into the spore suspension and wounding each fruit once. The temperature of the fruit at the time of inoculation and subsequent storage until treatment was $20^{\circ} \mathrm{C}\left( \pm 1^{\circ} \mathrm{C}\right)$. After all treatments were applied, the fruit were placed into plastic cavity trays that prevented contact infections. In every test, controls included fruit that were inoculated and treated with water and fruit that were inoculated and not treated.

Comparison of bicarbonate and carbonate solutions for the control of green mold on lemons. To determine if other bicarbonates or carbonates could effectively control green mold, inoculated lemons were immersed for 1.5 or $2 \mathrm{~min}$ in 22 liter volumes of water, SC, SBC, potassium carbonate, ammonium bicarbonate, or potassium bicarbonate. Each solution was applied at 27 or $40^{\circ} \mathrm{C}\left( \pm 1^{\circ} \mathrm{C}\right)$. The temperature of the solutions did not change more than $0.5^{\circ} \mathrm{C}$ during treatment. After treatment, the fruit were rinsed with $10 \mathrm{ml}$ of deionized water per fruit at low pressure $(200 \mathrm{kPa})$ in a spray $30 \mathrm{~cm}$ above the fruit over a period of $5 \mathrm{~s}$, stored for 2 or 3 weeks at 13 or $20^{\circ} \mathrm{C}\left( \pm 1^{\circ} \mathrm{C}\right)$, and the incidence of green mold-infected fruit was determined. The solutions contained equimolar or equal-weight quantities of bicarbonates or carbonates. Each treatment was applied to four or five replicates of 25 fruit each. The test was repeated three times, although not all bicarbonate and carbonate treatments were included in every test.

Comparison of SC and SBC for the control of green mold. SC and SBC solutions were compared on an equal-weight basis on lemons and oranges. Inoculated lemons $(C$. limon) cv. Eureka or oranges (C. sinensis) cv. Valencia were immersed for $2 \mathrm{~min}$ in 22 liters of water or in equalweight quantities of SC or SBC at 2 or $3 \%$ (wt/vol) at 40 or $45^{\circ} \mathrm{C}\left( \pm 1^{\circ} \mathrm{C}\right)$, rinsed with $10 \mathrm{ml}$ of water per fruit applied as previously described, stored for 2 or 3 weeks at 13 or $20^{\circ} \mathrm{C}\left( \pm 1^{\circ} \mathrm{C}\right)$, and the incidence of green mold infected fruit was determined. Each treatment was applied to four replicates of 25 fruit each. The test was repeated, with minor differences in procedure, three times with Eureka lemons and twice with Valencia oranges.

Influence of chlorination on SBC effectiveness. Solutions containing 0, 0.25, $0.5,1$, and $3 \%(\mathrm{wt} / \mathrm{vol}) \mathrm{SBC}$ were prepared, and an identical series of solutions was prepared with the addition of 200 $\mu \mathrm{g} / \mathrm{ml}$ of sodium hypochlorite. All were adjusted to $\mathrm{pH} 7.5$ with concentrated $\mathrm{HCl}$. Total chlorine content was periodically measured by combining a diluted sample of the hypochlorite-containing solutions with concentrated $\mathrm{HCl}$ and orthotolidine, and the absorbance at $500 \mathrm{~nm}$ was compared to a standard curve. The $\mathrm{pH}$ was measured repeatedly during the test and did not change. Inoculated lemons were immersed for $2 \mathrm{~min}$ in 22 liters of the SBC solutions at $25^{\circ} \mathrm{C}$, rinsed with $10 \mathrm{ml}$ of water per fruit applied at low pressure as previously described, and stored 2 weeks at $18^{\circ} \mathrm{C}\left( \pm 1^{\circ} \mathrm{C}\right)$. Each treatment was applied four times to replicates of 25 fruit each. The test was done once.

Influence of post-treatment water rinse volume on $\mathrm{SC}$ effectiveness. In a laboratory test, lemons inoculated $24 \mathrm{~h}$ earlier were immersed for $1.5 \mathrm{~min}$ in $3 \%$ (wt/vol) SC solution at $40.6^{\circ} \mathrm{C}\left( \pm 1^{\circ} \mathrm{C}\right)$. After treatment, the fruit were not rinsed or rinsed with 2,10 , or $50 \mathrm{ml}$ of deionized water per fruit applied at $200 \mathrm{kPa}$ in a spray $30 \mathrm{~cm}$ above the fruit over a period of 3 to $10 \mathrm{~s}$. Each treatment was applied to four replicates of 25 fruit each. The test was done once. In tests with commercial packing line equipment, fruit inoculated 24 $\mathrm{h}$ previously were placed for $60 \mathrm{~s}$ into a 2,400-liter-capacity tank containing 3\% (wt/vol) $\mathrm{SC}$ at $38^{\circ} \mathrm{C}\left( \pm 1^{\circ} \mathrm{C}\right)$. After treatment in the tank, the fruit were immediately rinsed with water $\left(16\right.$ to $\left.18^{\circ} \mathrm{C}\right)$ from three nozzles placed $20 \mathrm{~cm}$ apart and 33 $\mathrm{cm}$ above rotating brushes on a $60-\mathrm{cm}$ wide bed. The $80^{\circ}$ solid-cone nozzles were changed to vary water volumes and operated at a water pressure of $300 \mathrm{kPa}$. Fruit were not rinsed or rinsed after SC treatment with 2,10 , or $50 \mathrm{ml}$ per fruit applied during the approximately 1 -s residence period of the fruit under the rinse water nozzles. After rinsing, the fruit were dried for 15 to $20 \mathrm{~s}$ through a drier at $32.2^{\circ} \mathrm{C}$, a high solids content resin finishing wax (Sealbrite 504, EcoScience Corp., Orlando, CA) was applied, and the fruit were dried again for 15 to $20 \mathrm{~s}$ through a drier at $32.2^{\circ} \mathrm{C}$. The fruit were placed in fiber board cartons. All fruit were stored for 3 weeks at $10^{\circ} \mathrm{C}$ before the decayed fruit were counted. Within the test, each treatment was applied to four replicates of 60 to 
75 fruit each. The test was done once with $\mathrm{cv}$. Valencia oranges and twice with $\mathrm{cv}$. Eureka lemons.

Influence of high-pressure water washing on SC effectiveness. To determine the influence of high pressure water washing on SC effectiveness, inoculated lemons and oranges were treated with one of the following: (i) immersed in water for $1 \mathrm{~min}$ at $44^{\circ} \mathrm{C}$; (ii) washed in a high pressure water washer; (iii) immersed in $3 \%$ $\mathrm{SC}$ for 1 min at $44^{\circ} \mathrm{C}\left( \pm 1^{\circ} \mathrm{C}\right)$ without prior or post-treatment cleaning; (iv) washed in a high-pressure water washer and then immersed in $3 \% \mathrm{SC}$; or (v) immersed in $3 \% \mathrm{SC}$, then washed in a high-pressure water washer. The residence time in the pressure washer, which operated at 1,380 $\mathrm{kPa}$, was approximately $45 \mathrm{~s}$. The pressure washer was $61 \mathrm{~cm}$ wide, $3 \mathrm{~m}$ long, and contained 15 rows of three $45^{\circ}$ flat-fan nozzles per row. Each nozzle applied 100 $\mathrm{ml} / \mathrm{s}$ of water. The water in the pressure washer contained $10 \mu \mathrm{g} / \mathrm{ml}$ of sodium hypochorite. The fruit, which were not waxed after treatment, were placed in fiber board cartons and stored 4 for weeks at $10^{\circ} \mathrm{C}$ before the decayed fruit were counted. Each treatment was applied to four replicates of 60 to 75 fruit each. The test was repeated twice with navel oranges and done once with cv. Eureka lemons.

Influence of SC solution temperature on rind injury of oranges. Navel orange cvs. Atwood, Bonanza, Fisher, New Hall, and Thomson Improved, grown at the University of California Lindcove Citrus Research and Extension Center (Lindcove, $\mathrm{CA}$ ), were harvested and randomized. Fruit (pulp temperature 12 to $13^{\circ} \mathrm{C}$ ) were immersed in $3 \%$ SC maintained at 28, 33, 44, 50,56 , or $61^{\circ} \mathrm{C}\left( \pm 1^{\circ} \mathrm{C}\right)$ in a 2,000 -litercapacity tank for $1 \mathrm{~min}$, rinsed with approximately $10 \mathrm{ml}$ of water per fruit by an overhead spray over rotating brushes, waxed with a high solids content finishing wax containing 2,000 $\mu \mathrm{g} / \mathrm{ml}$ imazalil

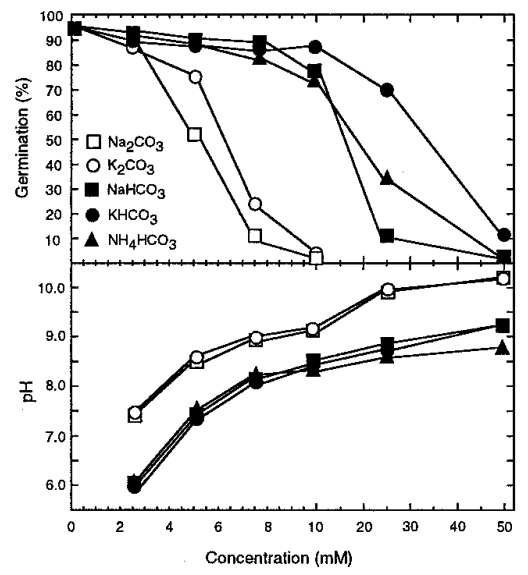

Fig. 1. The germination of spores of Penicillium digitatum after $24 \mathrm{~h}$ in potato dextrose broth in bicarbonate or carbonate solutions at the $\mathrm{pH}$ indicated.
(Fungaflor 500 EC, $44.6 \%$ a.i.; Janssen Pharmaceutica, Titusville, NJ), dried in a high-velocity, heated-air dryer, and placed into fiberboard cartons. Each treatment was applied to three replicates of 80 fruit of each cultivar. After storage for 3 weeks at $10^{\circ} \mathrm{C}$ with $90 \%$ relative humidity, fruit were classified into one of four categories, where 1 = no rind blemishes; 2 = slight blemishes present; $3=$ moderate blemishes present; and $4=$ severe rind injury. Fruit with rind injuries associated with classes 3 and 4 were of sufficient significance that the fruit could not normally be sold commercially without discount. The test was done once with each cultivar.

Influence of SC on the effectiveness of subsequent imazalil or biological control applications. Lemons or oranges were inoculated with $P$. digitatum as previously described, immersed $24 \mathrm{~h}$ later in 2 or $3 \%$ $\mathrm{SBC}$ or SC for $2.5 \mathrm{~min}$ at $40.5^{\circ} \mathrm{C}\left( \pm 1^{\circ} \mathrm{C}\right)$, and rinsed briefly with $10 \mathrm{ml}$ of water per fruit. Imazalil at $1,000 \mu \mathrm{g} / \mathrm{ml}$ in water or Pseudomonas syringae strain ESC10 (active ingredient of the registered product BioSave 10, a gift of EcoScience Corp.) at $10^{9} \mathrm{CFU} / \mathrm{ml}$ was applied by an overhead spray until the solutions ran off the surface of the fruit. The fruit were stored for 2 to 4 weeks at $10^{\circ} \mathrm{C}$ and the incidence of green mold infections was determined. Each treatment was applied to four or five replicates of 25 fruit each. The test was repeated twice.

Statistical analysis. The concentrations of salts that caused 50 and $95 \%$ mortality of spores and the upper and lower 95\% fiducial limits were estimated by Finney's Probit analysis (15). The incidence of green mold or rind injuries was analyzed by an analysis of variance applied to the square root of the arcsin of the proportion of infected or injured fruit, followed by Fisher's protected least significant difference (LSD) to separate means. Actual values are shown.

\section{RESULTS}

In vitro inhibition of spores of $P$. digitatum by bicarbonate and carbonate solutions. The $\mathrm{pH}$ of the unbuffered carbonate solutions were similar to each other and higher than the bicarbonate solutions at every concentration (Fig. 1). Fiducial limits of concentrations that inhibited $50 \%$ of the spores $\left(\mathrm{ED}_{50}\right)$ were narrower than those of $\mathrm{ED}_{95}$ concentrations (Table 1). The tox- icity of SC $\left(\mathrm{ED}_{50}=5.0 \mathrm{mM}\right)$ to spores of $P$. digitatum was significantly higher than potassium carbonate $\left(\mathrm{ED}_{50}=6.2 \mathrm{mM}\right)$. The toxicity of SBC $\left(\mathrm{ED}_{50}=14.1 \mathrm{mM}\right)$ to spores of $P$. digitatum was not significantly different than ammonium bicarbonate $\left(\mathrm{ED}_{50}=16.4 \mathrm{mM}\right)$, but significantly superior to potassium bicarbonate $\left(\mathrm{ED}_{50}=33.4\right.$ $\mathrm{mM})$. Spores removed from these solutions, rinsed in water, and incubated in potato dextrose broth for an additional $18 \mathrm{~h}$ had a germination rate of more than $99 \%$. In tests with bicarbonate salts where the $\mathrm{pH}$ was $7.2( \pm 0.2)$ with phosphate buffer, the $\mathrm{ED}_{50}$ concentrations of ammonium bicarbonate, SBC, and potassium bicarbonate were $34.4,37.2$, and $38.1 \mathrm{mM}$, respectively, and not significantly different from each other.

Comparison of bicarbonate and carbonate solutions for the control of green mold on lemons. The control of green mold was significantly better by SC or SBC solutions compared to potassium or ammonium solutions (Table 2).

Comparison of SC and SBC for the control of green mold. The control of citrus green mold by SBC and SC was not significantly different $(P \geq 0.05)$ in repeated tests with lemons and oranges (Fig. 2). Water alone at 40 or $43^{\circ} \mathrm{C}$ significantly reduced green mold in most tests compared to the untreated, inoculated controls, but the magnitude of the reduction was usually small.

Influence of chlorination on SBC effectiveness. The addition of $200 \mu \mathrm{g} / \mathrm{ml}$ of sodium hypochlorite to water or SBC slightly but significantly $(P=0.002)$ improved control of green mold on lemons (Fig. 3). The total chlorine content declined slightly from the beginning to the end of the test, from the initial $200 \mu \mathrm{g} / \mathrm{ml}$ to approximately $180 \mu \mathrm{g} / \mathrm{ml}$ after the treatments were applied. The $\mathrm{pH}$ and bicarbonate concentrations did not change during the test.

Influence of post-treatment water rinse volume on $\mathrm{SC}$ effectiveness. The volume of water sprayed onto fruit after SC treatment did not influence the effectiveness of the treatment to control green mold (Table 3).

Influence of high-pressure water washing on SC effectiveness. Washing fruit with water at high pressure significantly impacted control of green mold by SC treatment (Fig. 4). The incidence of

Table 1. Concentrations $(\mathrm{mM})$ of bicarbonate or carbonate salts that inhibited the germination of spores of Penicillium digitatum

\begin{tabular}{lcc}
\hline Salt & $\mathbf{E D}_{\mathbf{5 0}} \mathbf{z}$ & $\mathbf{E D}_{\mathbf{9 5}}$ \\
\hline $\mathrm{Na}_{2} \mathrm{CO}_{3}$ & $5.0(4.8,5.2)$ & $9.9(9.4,10.5)$ \\
$\mathrm{K}_{2} \mathrm{CO}_{3}$ & $6.2(5.3,7.0)$ & $9.6(8.5,13.4)$ \\
$\mathrm{NaHCO}_{3}$ & $14.1(13.4,14.9)$ & $31.0(28.4,34.4)$ \\
$\mathrm{NH}_{4} \mathrm{HCO}_{3}$ & $16.4(13.1,20.4)$ & $43.6(32.5,72.1)$ \\
$\mathrm{KHCO}_{3}$ & $33.4(31.5,35.4)$ & $70.6(63.4,81.4)$ \\
\hline
\end{tabular}

${ }^{\mathrm{z}} \mathrm{ED}=$ effective dose. Each value was calculated from three observations. Values in parenthesis are the upper and lower $95 \%$ fiducial limits. 
green mold among untreated, inoculated fruit was $98.3 \%$. When SC treatment was applied alone and the fruit were not rinsed after treatment, the green mold incidence was $18.2 \%$. When SC treatment was preceded by washing the inoculated fruit with water at high pressure, a further and significant reduction in green mold incidence to $9.5 \%$ occurred on cvs. Frost and Lane Late oranges, while on cv. Eureka lemons a slight but not significant improvement in carbonate effectiveness was observed. When SC treatment was followed by washing the inoculated fruit with water at high pressure, the incidence of green mold was $38.1 \%$. Pressure washing alone did not significantly reduce the incidence of green mold on oranges, but it slightly but significantly reduced green mold on lemons (Fig. 4). The green mold incidence of $97.0 \%$ among inoculated control lemons was reduced to $88.9 \%$ among those that were washed with water applied at high pressure.

Influence of SC solution temperature on rind injury of oranges. Phytotoxicity increased after SC treatment at 56 and $61{ }^{\circ} \mathrm{C}$ among navel oranges cvs. Atwood, Bonanza, Fisher, New Hall, and Thomson Improved, but not after treatment at 28, 33, 44 , or $50^{\circ} \mathrm{C}$ (Fig. 5). The cv. Thomson Improved had less injury than the other cultivars. Rind injuries were sunken areas 1 to $2 \mathrm{~mm}$ in depth that were light to dark brown in color.

Influence of SC on the effectiveness of subsequent biological control antagonist applications. $P$. syringae strain ESC10 significantly $(P \leq 0.001)$ improved the control of green mold when its application followed fruit treatments in heated solutions of water, SC, or SBC treatments (Fig. 6).

Influence of SC on the effectiveness of subsequent imazalil application. The incidence of green mold after the combination of SC treatment followed by treatment by imazalil was significantly lower than after either treatment alone. The incidence of green mold after inoculation alone, SC treatment alone, imazalil $(1,000$ $\mu \mathrm{g} / \mathrm{ml})$ treatment alone, or SC treatment followed by imazalil treatment was 61,36 , 22 , and $6 \%$, respectively. The incidence of green mold after the combined treatment was significantly less $(P \leq 0.001)$ than the imazalil or SC treatments alone.

\section{DISCUSSION}

The toxicity of SBC $\left(\mathrm{pH} 8.4 ; \mathrm{ED}_{50}=\right.$ $14.1 \mathrm{mM}$ ) to spores of $P$. digitatum was much less than that of $\mathrm{SC}\left(\mathrm{pH} 11.0 ; \mathrm{ED}_{50}=\right.$ $5.0 \mathrm{mM}$ ); however, they were similar in effectiveness for the control of green mold. Therefore, the $\mathrm{pH}$ and in vitro toxicity of the solutions did not predict the efficacy of the solutions to control green mold. Although $\mathrm{pH}$ values above 8.5 inhibit the germination and growth of $P$. digitatum $(10,26)$ and the higher $\mathrm{pH}$ of the carbonates enhanced their inhibitory activity in vivo, the equal performance of SBC and SC to control green mold demonstrates the $\mathrm{pH}$ of these solutions did not influence control of green mold significantly. Palmer and coworkers (30) and Homma and coworkers (10) showed that $\mathrm{pH}$ alone cannot explain the inhibitory action of these compounds. The $\mathrm{pH}$ of the solution deposited within the inoculation site was probably influenced by the albedo tissue of the rind, which is usually approximately $\mathrm{pH} 5.5$, and the $\mathrm{pH}$ of the residual of both bicarbonate and carbonate solutions within the infection sites may have been similar. Furthermore, sodium apparently had some role in the control of the disease because the sodium salts were superior to the ammonium and potassium carbonate and bicarbonate solutions. The superior performance of the sodium salts was not anticipated. We and

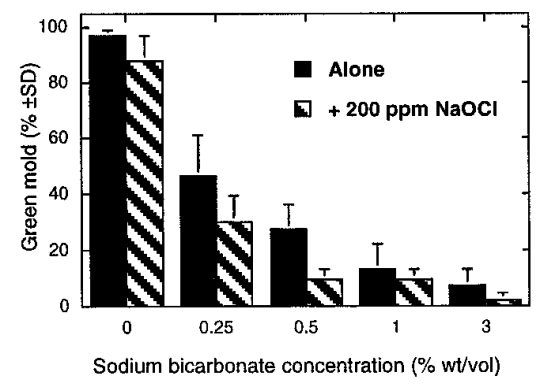

Fig. 3. The incidence of green mold on lemons after 2 min of treatment at $25^{\circ} \mathrm{C}$ in $\mathrm{pH} 7.5$ solutions of water alone or sodium bicarbonate with or without $200 \mu \mathrm{g} / \mathrm{ml}$ of sodium hypochlorite. Inoculated fruit were immersed in each solution for $2 \mathrm{~min}$ and stored for 2 weeks at $18^{\circ} \mathrm{C}$ before the incidence of green mold was determined.

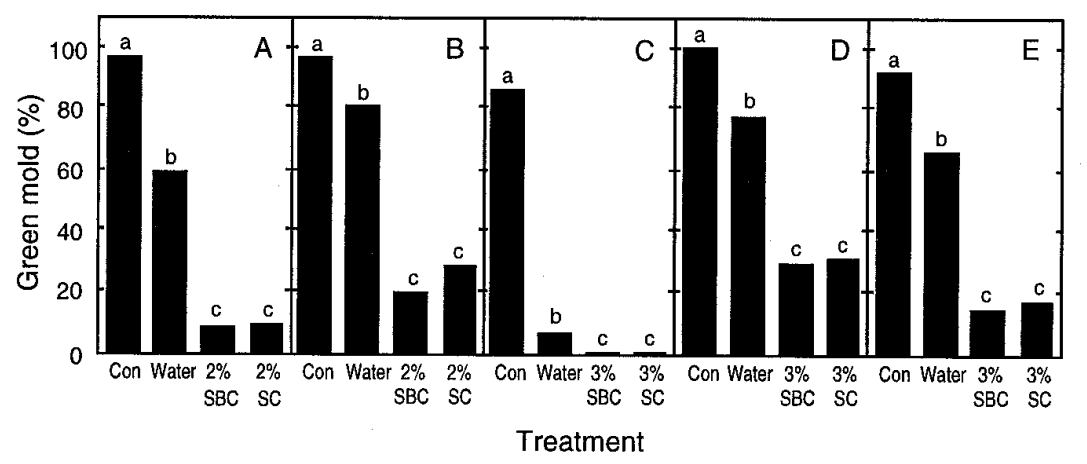

Fig. 2. The incidence of green mold on lemons or oranges after treatment in solutions of water alone or sodium carbonate (SC) or sodium bicarbonate (SBC) at 2 or $3 \%$ (wt/vol). Inoculated fruit were immersed in each solution for $2 \mathrm{~min}$, rinsed with $10 \mathrm{ml}$ of water per fruit, and stored 3 weeks at $13^{\circ} \mathrm{C}$ before the incidence of green mold was determined. (A) Treatment temperature $45^{\circ} \mathrm{C}$; in all other tests, temperature was $40^{\circ} \mathrm{C}$. (A) (B) and (C) Results with lemons; (D) and (E), results with cv. Valencia orange. Columns with unlike letters are significantly different by Fisher's least significant difference $(P \leq 0.05)$.

Table 2. The incidence of green mold on lemons after treatment in solutions of carbonate or bicarbonate salts

\begin{tabular}{|c|c|c|c|c|c|c|c|c|c|c|}
\hline \multirow[b]{2}{*}{ Treatment } & \multirow[b]{2}{*}{ pH } & \multicolumn{3}{|c|}{ Test no. $1^{x}$} & \multicolumn{3}{|c|}{ Test no. 2} & \multicolumn{3}{|c|}{ Test no. 3} \\
\hline & & $\mathbf{M}^{\mathbf{y}}$ & $\%$ & $\overline{\text { Green mold }(\%)^{\mathrm{z}}}$ & $\mathbf{M}$ & $\%$ & $\overline{\text { Green mold }(\%)}$ & $\mathbf{M}$ & $\%$ & Green mold (\%) \\
\hline Inoculated, not treated & NA & NA & NA & $87.5 \mathrm{a}$ & NA & NA & $99.0 \mathrm{a}$ & NA & NA & $99.7 \mathrm{a}$ \\
\hline Water & 7.2 & NA & NA & $67.5 \mathrm{~b}$ & NA & NA & $91.1 \mathrm{~b}$ & NA & NA & $97.6 \mathrm{a}$ \\
\hline $\mathrm{Na}_{2} \mathrm{CO}_{3}$ & 11.0 & 0.50 & 5.3 & $9.9 \mathrm{~d}$ & 0.28 & 3.0 & $20.0 \mathrm{~d}$ & 0.47 & 5.0 & $13.6 \mathrm{~d}$ \\
\hline $\mathrm{NaHCO}_{3}$ & 8.5 & 0.50 & 4.2 & $14.5 \mathrm{~d}$ & $\ldots$ & $\ldots$ & $\ldots$ & & $\ldots$ & $\ldots$ \\
\hline $\mathrm{K}_{2} \mathrm{CO}_{3}$ & 11.0 & & & & 0.30 & 3.0 & $33.0 \mathrm{c}$ & 0.50 & 5.0 & $27.2 \mathrm{c}$ \\
\hline $\mathrm{KHCO}_{3}$ & 8.4 & 0.50 & 5.0 & $23.4 \mathrm{c}$ & $\ldots$ & $\ldots$ & $\ldots$ & 0.50 & 5.0 & $41.6 \mathrm{~b}$ \\
\hline $\mathrm{NH}_{4} \mathrm{HCO}_{3}$ & 7.6 & 0.50 & 4.0 & $24.4 \mathrm{c}$ & 0.38 & 3.0 & $39.0 \mathrm{c}$ & $\ldots$ & $\ldots$ & $\ldots$ \\
\hline
\end{tabular}

x Values in test 1 are the means of 10 replicates of 25 lemons each, immersed for 2 min at $26^{\circ} \mathrm{C}$ and stored for 3 weeks at $13^{\circ} \mathrm{C}$; values in test 2 are the means of 4 replicates of 25 each, immersed for $2 \mathrm{~min}$ at $40^{\circ} \mathrm{C}$ and stored for 2 weeks at $20^{\circ} \mathrm{C}$; values in test 3 are the means of 5 replicates of 25 each, immersed for $1.5 \mathrm{~min}$ at $40^{\circ} \mathrm{C}$ and stored for 2 weeks at $20^{\circ} \mathrm{C}$.

y $\mathrm{M}=$ concentration in molarity; $\%=$ concentration in $\mathrm{wt} / \mathrm{vol} ; \mathrm{NA}=$ not applicable; $\ldots=$ treatment not applied.

z Values within columns followed by unlike letters are significantly different $(P \leq 0.05)$ by Fisher's least significant difference applied after an analysis of variance of arcsin transformed values. Actual data are shown. 
other workers have shown that sodium, potassium, and ammonium bicarbonates have similar inhibitory activity against spores (Fig. 1; 29,30), and they were equal to or superior to SBC for the control of other diseases $(18,29)$. Ammonium bicarbonate in particular would be anticipated to be effective, because ammonia and ammonium salts have been used to control green mold (39).

This work offers partial solutions for the disposal of the process water from packinghouses, where the discharge to ponds or sewers of various solutions used to treat citrus, namely borax-boric acid, sodium ortho-phenyl phenate, and SC, is under regulatory control. An equivalent-weight solution of SBC has a lower $\mathrm{pH}$ and less sodium than a similar solution of $\mathrm{SC}$. Equimolar amounts of SBC contain $27.4 \%$ sodium compared to $43.4 \%$ sodium in SC. Another very significant advantage of bicarbonate salts is that they can be effectively chlorinated, because at the $\mathrm{pH}$ of these solutions a substantial portion of the hypochlorite is protonated and active. The addition of $200 \mu \mathrm{g} / \mathrm{ml}$ of sodium hypochlorite to $\mathrm{SBC}$ at $\mathrm{pH} 7.5$ slightly but significantly improved control of green mold on lemons, and the hypochlorite will kill spores and other microbes contaminating the solution. A disadvantage of SBC is that heating the solution will cause carbon dioxide evolution into air with a concomitant increase in solution $\mathrm{pH}$. At ambient temperatures, carbon dioxide evolution from bicarbonate solution is not significant and the $\mathrm{pH}$ of the solution does not change. Unfortunately, heating sometimes significantly improved carbonate and bicarbonate solution effectiveness in practical tests. Heating of the solutions to $60^{\circ} \mathrm{C}$ when fruit are not present, a practice used to sanitize SC solutions of contaminating microbes and spores, cannot be done with SBC, but the addition of hypochlorite to SBC should accomplish this task. Other carbonate or

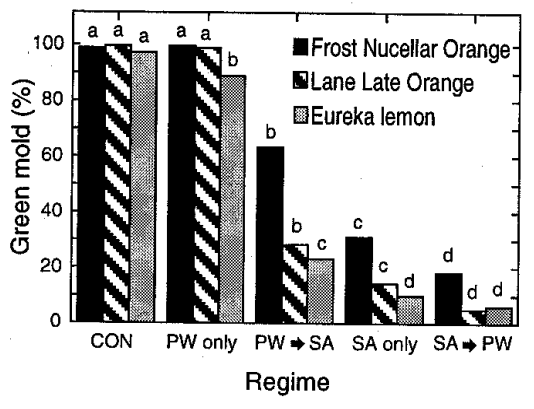

Fig. 4. The incidence of green mold on lemons or oranges after treatment in regimes where the fruit were inoculated and not treated (CON); inoculated and washed with water at high pressure (PW only); treated with sodium carbonate, then washed with water at high pressure $(\mathrm{SA} \rightarrow$ PW); treated with sodium carbonate alone (SA only); or washed with water at high pressure, then treated with sodium carbonate (PW $\rightarrow$ SA). bicarbonate salts could be adopted but they are less effective than SBC and SC. In other work, we that showed ethanol and sulfur dioxide could replace SC, although they were less effective (36). Other solutions that are suitable for discharge to sewers or ponds, applied to land as soil amendments or fertilizers, or recycled, should be examined for this application.

The solutions we tested must be rinsed off the surface of the fruit to prevent the deposition of the salts on brushes and belts of packing and sorting equipment, and to prevent staining and desiccation of the fruit rind. Marloth (26) and Hwang and Klotz (22) reported the effect of carbonate or bicarbonate solutions on spores of $P$. digitatum was primarily fungistatic; many spores remained germinable after exposures of $5 \mathrm{~min}$ or longer in $10 \%(\mathrm{wt} / \mathrm{vol})$ $\mathrm{Na}_{2} \mathrm{CO}_{3}$ or $\mathrm{NaHCO}_{3}$. Spores survive the treatments of 1 or $2 \mathrm{~min}$ in duration that control green mold on fruit (34); therefore, it is probable that a residue of carbonate or bicarbonate must remain on the fruit, or at least within the wound infection courts occupied by this pathogen, for the treatment to inhibit infection. Water rinsing by

Table 3. Incidence of green mold after sodium carbonate treatment followed by a water rinse and 3 weeks of storage at $10^{\circ} \mathrm{C}$

\begin{tabular}{lrccc}
\hline & \multicolumn{4}{c}{ Green mold incidence $(\boldsymbol{\%})^{\mathbf{z}}$} \\
\cline { 2 - 4 } Rinse volume per fruit $(\mathbf{m l})$ & Test $\mathbf{1}$ & Test 2 & Test 3 & Mean \\
\hline Inoculated, not treated & $96.8 \mathrm{a}$ & $96.7 \mathrm{a}$ & $84.6 \mathrm{a}$ & $92.7 \mathrm{a}$ \\
0 & $9.6 \mathrm{~b}$ & $22.7 \mathrm{~b}$ & $11.7 \mathrm{~b}$ & $14.7 \mathrm{~b}$ \\
2 & $20.0 \mathrm{~b}$ & $12.0 \mathrm{~b}$ & $13.3 \mathrm{~b}$ & $15.1 \mathrm{~b}$ \\
10 & $13.6 \mathrm{~b}$ & $16.1 \mathrm{~b}$ & $5.8 \mathrm{c}$ & $11.8 \mathrm{~b}$ \\
50 & $19.2 \mathrm{~b}$ & $18.0 \mathrm{~b}$ & $8.8 \mathrm{bc}$ & $15.3 \mathrm{~b}$ \\
\hline
\end{tabular}

z Test $1=$ lemons, $n=5$ replicates of 25 ; test $2=$ lemons, 4 replicates of 75 ; test $3=$ oranges, 4 replicates of 60 . Test 1 was a laboratory test; tests 2 and 3 were done with commercial packing equipment.

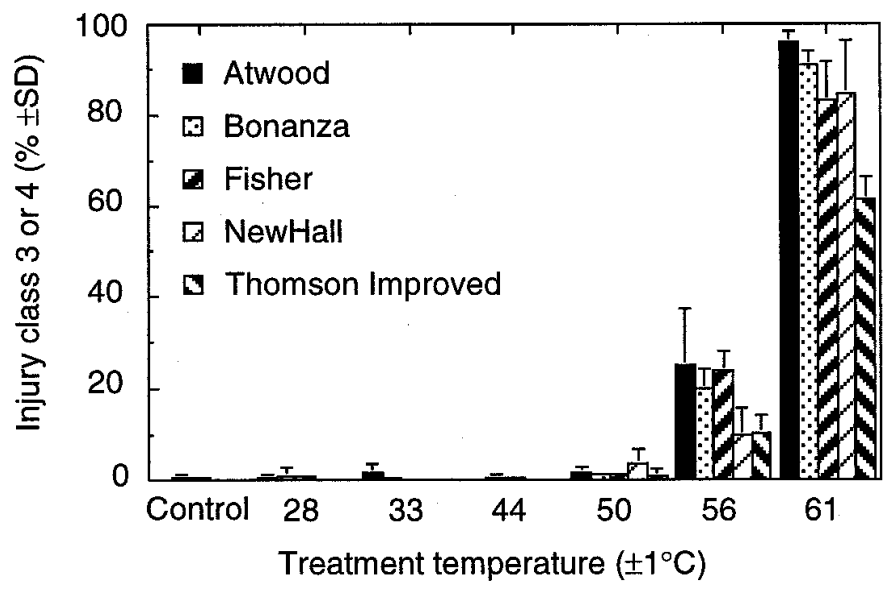

Fig. 5. Influence of the temperature of sodium carbonate treatment ( $3 \% \mathrm{wt} / \mathrm{vol}$ for $1 \mathrm{~min})$ on the appearance of oranges after treatment and storage at $10^{\circ} \mathrm{C}$ for 3 weeks. Injury classes: $1=$ no rind blemishes; 2 = slight blemishes present; $3=$ moderate blemishes present; and $4=$ severe rind injury.

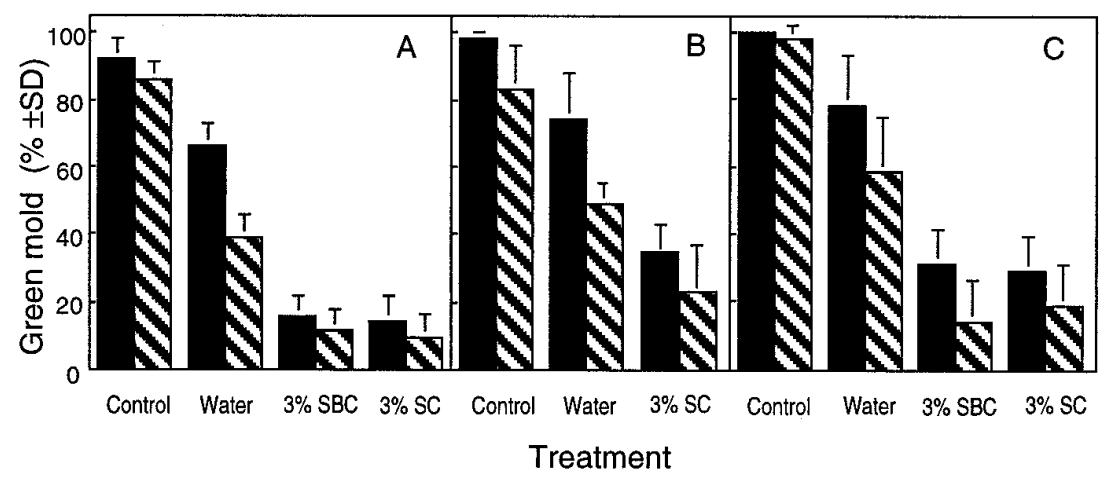

Fig. 6. The incidence of green mold on cv. Valencia oranges after immersion in water or in solutions of $3 \%$ sodium bicarbonate (SBC) or 3\% sodium carbonate (SC) alone (solid bar) or each followed by the application of Pseudomonas syringae strain ESC10 (striped bar). (A) Treatment solution temperature $=45^{\circ} \mathrm{C} ;(\mathbf{B})$ and $(\mathbf{C})$ treatment solution temperature $=40^{\circ} \mathrm{C}$. 
low-pressure overhead sprays, typically used for this purpose, did not influence SC effectiveness significantly, while highpressure water washing significantly diminished its efficacy. High-pressure water washing, and probably other fruit-washing procedures that employ extensive brushing, soaps, and high water volumes, reduce SC effectiveness because this residue is removed. Presumably, the residue persists through low-pressure water rinses but it is substantially removed by high-pressure water washing of fruit. We were unable to correlate rind sodium content and SC effectiveness because the sodium content of the rind of lemons and oranges was naturally high (about $130 \mu \mathrm{g} / \mathrm{g}$ fresh wt) and variable.

Citrus fruit should be cleaned before SC treatment because the effectiveness of SC treatment will be diminished if they are washed rigorously afterward. Two other benefits of washing the fruit before SC treatment were considered. First, residual SC remaining on treated fruit would not contaminate the water of the pressure washer. SC would raise the $\mathrm{pH}$ of the water and diminish the efficacy of the sodium hypochlorite used to sanitize the pressure washer water. Second, if the fruit are cleaned before they enter the SC tank, the solution will remain cleaner and require less frequent replacement. A disadvantage of this sequence is that cleaning of fruit may require higher water pressure that may increase the risk of mechanical injury to the rind. Some managers report SC treatment prior to pressure washing partially cleans and conditions soiled fruit so cleaning can be accomplished with lower water pressure.

Washing inoculated fruit with water applied at high pressure alone did not reduce the incidence of green mold on oranges, and slightly but significantly reduced it on lemons. Pressure washing also may have affected a mechanical removal of some of the germlings. Other workers reported that green mold incidence is reduced when wounds on fruit are rigorously rinsed and then inoculated, because washing removes nutrients that stimulate $P$. digitatum spore germination (1) or removes rind oils that retard the lignification of wounds (3). The inoculum may have been reduced by mechanical removal of the germlings by highpressure water washing in our tests.

The risk of SC injury to citrus fruit has been discussed previously $(13,23,35,36)$. In the present work, rind injuries were only associated with $\mathrm{SC}$ treatments at $56^{\circ} \mathrm{C}$ or higher. Therefore, the risk of injury is low because these temperatures are above that needed for the control of green mold (35). In addition to visible scalding injury to the rind, harsh chemical (16) or hot-water treatments exceeding $48^{\circ} \mathrm{C}(17,27)$ can render the fruit susceptible to infection without obvious wounds, although $P$. digitatum typically requires wounds for infec- tion to occur. Compared to hot water alone, $\mathrm{SC}$ is effective for the control of green mold at much lower temperatures $(35,37)$, so the risk of injury to the fruit is reduced $(21,24)$. A reason to use SC at higher temperatures $\left(50^{\circ} \mathrm{C}\right)$ is to control brown rot, caused by Phytophthora spp. (14). Its control requires temperatures (25) that occasionally injure fruit (24). Brown rot is usually of less concern than green mold (10) and is associated with high rainfall and poor cultural practices (14). Carbonate and bicarbonate treatments inhibit the growth of the pathogen, but do not injure the fruit or its defensive responses. SC treatment at $40^{\circ} \mathrm{C}$ did not influence the synthesis of phloroglucinol-positive compounds within wounds associated with inhibition of infection by $P$. digitatum by lemon fruit (37; R. R. Stang, personal communication).

The effectiveness of SBC and SC was significantly improved when these treatments were followed by the fungicide imazalil or $P$. syringae strain ESC10. The combination of bicarbonate or carbonate followed by the biological control antagonist $P$. syringae overcomes significant shortcomings of either of these treatments alone. Biological control antagonists are poor eradicants that are usually incapable of controlling green mold when the fruit are inoculated $24 \mathrm{~h}$ before treatment (34), while imazalil, SC, and SBC can control these infections. SC and SBC do not provide persistent protection of the fruit from re-infection after treatment, while residues of imazalil or biological control antagonists persist for long periods after treatment and protect fruit from re-infection. Apparently, the residual of the bicarbonate or carbonate solutions that remained in inoculated wounds on the fruit was tolerated by the antagonist but inhibitory to the pathogen. For this combination to be used reliably under commercial conditions, a study of the tolerance of the antagonists to the bicarbonate and carbonate solutions and the influence of their residues on the populations of the antagonists in wounds on fruit is needed.

\section{ACKNOWLEDGMENTS}

We thank the California Citrus Research Board for assistance; D. Sorenson of Sunkist Growers, Lindsay, California; A. El-Gaouth of USDA-ARS, Kearneysville, West Virginia; J. Stack of EcoScience Corp., Orlando, California; J. W. Eckert of the University of California, Riverside; and J. Maze, W. Stutzman, and L. Whitendale of the University of California, Lindcove.

\section{LITERATURE CITED}

1. Arimoto, Y., Sugawara, F., Yoshida, S., and Yamaguchi, I. 1995. Prangolarin is a chemical facilitator for the enhanced development of the infection process in the epicarp of Citrus limon by Penicillium digitatum. J. Agric. Food Chem. 43:2283-2285.

2. Barger, W. R. 1928. Sodium bicarbonate as a citrus fruit disinfectant. Calif. Citrogr. 13:164-174.

3. Brown, G. E. 1973. Development of green mold in degreened oranges. Phytopathology
63:1104-1107.

4. Brown, G. E., and Chambers, M. 1996. Evaluation of biological products for the control of postharvest diseases of Florida citrus. Proc. Fla. State Hortic. Soc. 109:278-282.

5. Brown, G. E., Miller, W. R., and McDonald, R. E. 1991. Control of green mold in Marsh grapefruit with vapor heat quarantine treatment. Proc. Fla. State Hortic. Soc. 104:115117.

6. Bus, V. G., Bongers, A. J., and Risse, L. A. 1991. Occurrence of Penicillium digitatum and P. italicum resistant to benomyl, thiabendazole, and imazalil on citrus fruit from different geographic origins. Plant Dis. 75:10981100 .

7. Cohen, E. 1991. The use of temperature for postharvest decay control in citrus fruit. Pages 256-263 in: Biol. Control Postharvest Dis. Fruits Veg. Workshop Proc. Sheperdstown, WV.

8. Corral, L. G., Post, L. S., and Montville, T. J. 1988. Antimicrobial activity of sodium bicarbonate. J. Food Sci. 53:981-982.

9. Eckert, J. W., and Brown, G. E. 1986 Evaluation of postharvest treatments for citrus fruits. Pages 92-97 in: Methods for Evaluating Pesticides for Control of Plant Pathogens. K. D. Hickey, ed. American Phytopathological Society, St. Paul, MN.

10. Eckert, J. W., and Eaks, I. L. 1989. Postharvest disorders and diseases of citrus fruits. Pages 179-260 in: The Citrus Industry. Vol. 4. W. Reuther, E. C. Calavan, and G. E. Carman, eds. University of California Press, Berkeley.

11. Eckert, J. W., Sievert, J. R., and Ratnayake, M. 1994. Reduction of imazalil effectiveness against citrus green mold in California packinghouses by resistant biotypes of Penicillium digitatum. Plant Dis. 78:971-974.

12. Fallik, E., Grinberg, S., and Ziv, O. 1997. Potassium bicarbonate reduces postharvest decay development on bell pepper fruits. J. Hortic. Sci. 72:35-41

13. Fawcett, H. S. 1936. Citrus Diseases and Their Control. Second edition. McGraw Hill, New York.

14. Feld, S. J., Menge, J. A., and Pehrson, J. E. 1979. Brown rot of citrus: a review of the disease. Citrograph 64:101-106.

15. Finney, D. J. 1971. Probit Analysis. Second edition. Cambridge University Press, Cambridge.

16. Green, F. M. 1932. The infection of oranges by Penicillium. J. Pomol. Hortic. Sci. 10:184 215.

17. Harding, P. R., and Savage, D. C. 1964. Investigation of possible correlation of hot-water washing with excessive storage decay in coastal California lemon packing houses. Plant Dis. Rep. 48:808-810.

18. Homma, Y., Arimoto, Y., and Misato, T. 1981. Effects of emulsifiers and surfactants on the protective values of sodium bicarbonate. J. Pestic. Sci. 6:145-153.

19. Horst, R. K., Kawamoto, S. O., and Porter, L. L. 1992. Effect of sodium bicarbonate and oils on the control of powdery mildew and black spot of roses. Plant Dis. 76:247-251

20. Houck, L. G. 1965. Penicillium development in lemons treated with 2,6-dichloro-4-nitroaniline. Plant Dis. Rep. 49:715-719.

21. Houck, L. G. 1967. Hot water treatments for control of Penicillium green mold of Eureka lemons. (Abstr.) Phytopathology 57:99.

22. Hwang, L., and Klotz, L. J. 1938. The toxic effect of certain chemical solutions on spores of Penicillium italicum and P. digitatum. Hilgardia 12:1-38.

23. Klotz, L. J. 1973. Color Handbook of Citrus Diseases. University of California, Berkeley.

24. Klotz, L. J., and DeWolfe, T. A. 1961. Limitations of the hot water immersion treatment 
for the control of Phytophthora brown rot of lemons. Plant Dis. Rep. 45:264-267.

25. Klotz, L. J., and DeWolfe, T. A. 1961. Brown rot contact infection of citrus fruits prior to hot water treatment. Plant Dis. Rep. 45:268271 .

26. Marloth, R. H. 1931. The influence of hydrogen-ion concentration and of sodium bicarbonate and related substances on Penicillium italicum and $P$. digitatum. Phytopathology 21:169-198.

27. McGuire, R. G., and Hagenmaier, R. D 1996. Shellac coatings for grapefruits that favor biological control of Penicillium digitatum by Candida oleophila. Biol. Control 7:100-106.

28. Miyasaki, K. T., Genco, R. J., and Wilson, M. E. 1986. Antimicrobial properties of hydrogen peroxide and sodium bicarbonate individually and in combination against selected oral, gram-negative, facultative bacteria. J. Dent. Res. 65:1142.

29. Oliver, C., Halseth, D. E., Mizubuti, E. S. G., and Loria, R. 1998. Postharvest application of organic salts for suppression of silver scurf on potato tubers. Plant Dis. 82:213-217.

30. Palmer, C. L., Horst, R. K., and Langhans, R. W. 1997. Use of bicarbonates to inhibit in vitro colony growth of Botrytis cinerea. Plant Dis. 81:1432-1438

31. Pelser, P. du T. 1974. Recommendations for the Control of Post-harvest Decay of Citrus Fruits. South African Co-operative Citrus Exchange Ltd.

32. Powell, G. H. 1908. The decay of oranges while in transit from California. Bur. Plant Ind. U. S. Dep. Agric. Bull. 123

33. Punja, Z. K., and Grogan, R. G. 1982. Effects of inorganic salts, carbonate-bicarbonate anions, ammonia, and the modifying influence of $\mathrm{pH}$ on sclerotial germination of Sclerotium rolfsii. Phytopathology 72:635-639.

34. Smilanick, J. L., and Denis-Arrue, R. 1992. Control of green mold of lemons with $\mathrm{Pseu}$ domonas species. Plant Dis. 76:481-485.

35. Smilanick, J. L., Mackey, B. E., Reese, R., Usall, J., and Margosan, D. A. 1997. Influence of the concentration of soda ash, temperature, and immersion period on the control of postharvest green mold of oranges. Plant
Dis. 81:379-382.

36. Smilanick, J. L., Margosan, D. A., and Henson, D. J. 1995. Evaluation of heated solutions of sulfur dioxide, ethanol, and hydrogen peroxide to control postharvest green mold of lemons. Plant Dis. 79:742-747.

37. Smoot, J. J., and Melvin, C. F. 1965. Reduction of citrus decay by hot-water treatment. Plant Dis. Rep. 49:463-467.

38. Stang, R.R., Midland, S. L., Eckert, J. W., and Sims, J. J. 1993. An antifungal compound produced by grapefruit and valencia orange after wounding of the peel. J. Nat. Prod. 56:1627-1629.

39. Tomkins, R. G., and Trout, S. A. 1931. The use of ammonia and ammonium salts for the prevention of green mold in citrus. J. Pomol. Hortic. Sci. 9:257-264.

40. Winston, J. R. 1935. Reducing decay in citrus fruits with borax. U. S. Dep. Agric. Tech. Bull. 488.

41. Ziv, O., and Zitter, T. A. 1992. Effects of bicarbonate and film-forming polymers on cucurbit foliar diseases. Plant Dis. 76:513517. 